\title{
Trata con fines de explotación sexual. Derechos humanos que mal- tratan a las humanas
}

Trafficking for sexual explotation. Human Rights that exploit human beings

\author{
Nuria Cordero Ramos \\ Profesora Titular del Departamento de Trabajo Social y Servicios Sociales. Universidad Pablo de Olavide, Sevilla (España) \\ ncorram@upo.es
}

\author{
CUERPOS, SEXUALIDADES YPODER \\ MONOGRÁFICO COORDINADO POR JOSÉ MARIA VALCUENDE. Universidad Pablo de Olavide (Sevilla).
}

\begin{abstract}
RESUMEN
A partir del trabajo desarrollado en el marco del Proyecto de investigación I+D, "Laboratorio Iberoamericano para el Estudio Sociohistórico de las Sexualidades", financiado por el Ministerio de Economía y Competitividad (FEM2011-27295), sobre la trata de personas con fines de explotación sexual, se plantean una serie de reflexiones críticas que apuntan a los discursos institucionales relativos a la defensa de los derechos humanos. La finalidad que se persigue es visibilizar las lógicas dominantes en las propuestas normativas e institucionales vigentes, así como mostrar las aportaciones desde un enfoque crítico de los derechos humanos. Ambas perspectivas tienen consecuencias directas y distintas en relación con la dignidad de las personas, en su mayoría mujeres, que padecen situaciones de trata con fines de explotación sexual.
\end{abstract}

\section{ABSTRACT}

From the work undertaken as a subject for the project of investigation I+D, "Laboratorio Iberoamericano para el Estudio Sociohistórico de las Sexualidades" financed by Ministerio de Economía y Competitividad (FEM2011-27295) about the trafficking for the exploitation of people with sexual purposes, a number of critical reflexions made regarding the institutional speeches about the defence of human rights. The purpose pursued is to show the dominant logic about the current rules and show the contribution of a critical look at human rights as well. The two views are related but sharply different regarding the dignity of people, mainly women, suffering trafficking for sexual purposes.

PALABRAS ClAVE

trata de personas | tráfico de personas | prostitución | derechos humanos | mujeres

KEYWO RDS

trafficking in persons | prostitution | human rights | women

\begin{abstract}
"No hay mujer que no resulte sospechosa de mala conducta. Según los boleros, son todas ingratas. Según los tangos, son todas putas (menos mamá). Confirmaciones del derecho de propiedad: el macho propietario comprueba a golpes su derecho de propiedad sobre la hembra (...). Vuela torcida la humanidad, pájaro de un ala sola" (Eduardo Galeano).
\end{abstract}

\section{Aproximaciones a la "trata" con fines de explotación sexual}

El fenómeno de la trata de personas con fines de explotación sexual no se puede entender como una cuestión aislada de las lógicas de dominación patriarcal y neoliberal que sitúan a las personas como medios al servicio de sus propios fines. En este trabajo, que ahonda sobre los contenidos recogidos en la obra Diversidad Sexual en Iberoamérica (2013) y en la comunicación que presenté al III Congreso para el estudio de violencia contra las mujeres. Justicia y seguridad (2012), partimos de la consideración de que la trata de personas con fines de explotación sexual es una forma de esclavitud que priva de condiciones de vida digna a quienes la padecen.

Aunque el fenómeno de la trata de personas comenzó a formar parte de las agendas políticas hace algo más de una década, estamos ante una cuestión tan antigua como la propia esclavitud. En la época colonial las mujeres y niñas indígenas eran trasladadas de sus lugares de origen, convirtiéndose en objetos de comercialización con finalidades sexuales y de servidumbre por parte y al servicio de los hombres blancos. Sin embargo, estas situaciones empezaron a categorizarse como problema social a fines del siglo XIX e 
inicios del $\mathrm{XX}$, precisamente cuando las mujeres blancas fueron captadas para servir como prostitutas o concubinas generalmente en países árabes, africanos o asiáticos. A partir de ese momento, la erradicación de lo que se denominó "trata de blancas" fue uno de los objetivos de los movimientos abolicionista contra la prostitución.

La preocupación internacional por esta cuestión se manifiesta con la aprobación en 1949, por parte de la Asamblea General de las Naciones Unidas, del Convenio para la represión de la trata de personas y la explotación de la prostitución ajena. La importancia de este documento es que amplía a todas las personas (y no sólo a las mujeres y niños) la posibilidad de padecer situaciones de trata. Dicho Convenio condena la prostitución o su incitación, aunque hubiera consentimiento (Juliano 2005). Desde entonces, y hasta la actualidad, la confusión entre trata y prostitución sigue presente tanto en discursos institucionales como en los debates políticos.

Tras varias décadas sin protagonismo en las agendas políticas, la trata de mujeres con fines de explotación sexual vuelve a tomar fuerza a nivel internacional, debido fundamentalmente al incremento de la migración en general y consiguiente llamativo aumento de la cifra de mujeres afectadas. Estos desplazamientos masivos de poblaciones de unas regiones del mundo a otras en busca de mejores condiciones de vida, originó la mercantilización de los traslados, surgiendo la denominación de tráfico humano o tráfico de personas.

La Oficina contra la Droga y el Delito (ONUDD) de la ONU acuñó así los términos "trata de personas" o "trata de seres humanos", traducidos del inglés trafficking in persons o trafficking in human beings. Sin embargo, la ONUDD es crítica con su propia definición ya que entiende que es un término confuso que oculta el fenómeno de la esclavitud, afirmando que "la expresión trata de personas puede inducir a error: hace hincapié en los aspectos de operación comercial de un delito que puede definirse con mayor exactitud como esclavización" (ONUDD 2009: 2). Dicho organismo realizó en el año 2000 un esfuerzo por aclarar su significado y abarcar las realidades que integran el fenómeno de la trata, celebrando la Convención contra la Delincuencia Organizada Transnacional y elaborando tres protocolos que complementan su contenido.

En concreto, en el Protocolo para prevenir, reprimir y sancionar la trata de personas, especialmente mujeres y niños, conocido como el Protocolo de Palermo (2000), se define la trata de personas en su artículo 3 como:

"la captación, el transporte, el traslado, la acogida o la recepción de personas, recurriendo a la amenaza o al uso de la fuerza u otras formas de coacción, al rapto, al fraude, al engaño, al abuso de poder o de una situación de vulnerabilidad o a la concesión o recepción de pagos o beneficios para obtener el consentimiento de una persona que tenga autoridad sobre otra, con fines de explotación. Esa explotación incluirá, como mínimo, la explotación de la prostitución ajena u otras formas de explotación sexual, los trabajos o servicios forzados, la esclavitud o las prácticas análogas a la esclavitud, la servidumbre o la extracción de órganos".

Esta definición internacional hace el intento de aclarar y alcanzar consenso acerca del fenómeno de la trata, diferenciándolo tanto de la prostitución como del tráfico de migrantes. En su contenido se distinguen tres elementos constitutivos de la trata: por una lado, los actos que permiten conseguir a las víctimas (captarlas, trasladarlas, acogerlas y/o recepcionarlas); por otro, los medios que se utilizan para obligarlas (amenazas, uso de la fuerza, coacción, rapto, fraude, engaño, abuso de poder, abuso de una situación de vulnerabilidad, concesión, así como recepción de pagos o beneficios para obtener el consentimiento de una persona que tenga autoridad sobre otra); y, por último, los fines para los que se quiere a esas víctimas (ganar dinero o favores a costa de las víctimas, para lo cual éstas son explotadas sexualmente, laboralmente, obligadas a la servidumbre, la mendicidad, la extracción de órganos u otros tipos de explotación). Según la ONUDD (2009: 2), de todas estas formas de trata de personas en el ámbito mundial, la explotación sexual es la detectada con más frecuencia (79\%), lo que podría ser el resultado de un sesgo estadístico, ya que esta suele ser vista, a ojos de la ciudadanía, como mera prostitución (Cordero y otros 2012: 19).

Es importante resaltar que la trata de seres humanos con fines de explotación sexual es un fenómeno que está en expansión desde la lógica dominante de una sensibilidad "mercadocéntrica", que tiende a objetualizar no sólo todas las cosas, sino también hasta a las personas. La esclavitud sexual genera grandes beneficios y los riesgos se minimizan a través de la violencia y del miedo que se ejerce sobre quienes la padecen. Se sabe que el número de víctimas, lejos de disminuir, va en aumento, aunque es muy difícil precisar, debido a su naturaleza clandestina y a los problemas relacionados con la detección, la identificación de casos de trata y la tolerancia social. La masificación de los desplazamientos humanos, la 
existencia de prejuicios sociales y el miedo, entre otros, son algunos de los aliados para la ampliación a pasos agigantados de este fenómeno, que sucede ante la impasibilidad de buena parte de la sociedad. Tomando como referente las cifras de la Organización Internacional de las Migraciones (OIM), se puede afirmar que existe más de un millón de personas que son víctimas de trata, entre las que el $80 \%$ son mujeres y, más de un $20 \%$, víctimas de explotación sexual.

Estas cifras han puesto en alerta a la comunidad internacional, llevándola a coordinar esfuerzos mediante la creación de organismos relacionados con la trata de personas. Destaca la Iniciativa Mundial de Naciones Unidas de Lucha contra la Trata de Personas (UN.GIFT), creada en marzo de 2007, en la que intervienen los siguientes organismos: la Organización Internacional del Trabajo (OIT), el Alto Comisionado de las Naciones Unidas para los Refugiados (ACNUR), el Fondo de las Naciones Unidas para la Infancia (UNICEF), la Oficina de Naciones Unidas contra la Droga y el Delito (ONUDD), la Organización Internacional para las Migraciones (OIM) y la Organización para la Seguridad y la Cooperación en Europa (OSCE). Con la creación de la UN.GIFT estas instituciones pretenden promover la lucha mundial contra la trata de personas, sobre la base de los acuerdos internacionales alcanzados en la ONU, como es, entre otros, el ya mencionado Protocolo de Palermo. Sin embargo, este problema requiere estrategias globales y multisectoriales que comprendan los esfuerzos nacionales (de las instituciones estatales y los organismos no gubernamentales con alcance interno) y de organismos internacionales que incorporen una lógica de los derechos humanos que vaya más allá de los enfoques normativos y criminológicos (Cordero y otros 2012: 21).

\section{Lógicas dominantes en los discursos sobre derechos humanos}

Como se ha venido diciendo, a partir del año 2000 se inician los esfuerzos a nivel mundial, encabezados por Naciones Unidas (ONU), para proteger a las víctimas de los diferentes tipos de explotación humana. Entre los objetivos estaba el establecer una coordinación efectiva entre países con el propósito de obtener datos veraces para proceder a desarrollar y aplicar medidas legales que permitieran combatirla con conocimiento de causa. Sin embargo, se constata una impunidad que hace que la oferta y la demanda de personas esclavas se mantengan (MZC 2009: 15), ya que no todas las naciones cumplen y acatan los tratados firmados, junto al hecho de que las leyes nacionales dictadas para combatir la trata no suelen desarrollarse de forma completa o las pautas de las sentencias no se aplican con total rotundidad.

Los países que han ratificado el convenio de Palermo manifiestan una preocupación y una voluntad crecientes de implicación en la temática, aunque con diferentes intensidades. De forma general, se puede afirmar que todos, cada cual con su especificidad, han puesto en marcha medidas, tanto por parte de las entidades gubernamentales y no gubernamentales, dirigidas a consolidar acciones para combatir, prevenir, mejorar la atención de las víctimas, y todo ello en nombre de la protección de los derechos humanos.

Cuando se hace referencia a los derechos humanos es imprescindible aclarar qué se quiere decir, pues existe una especie de saturación malsana en la utilización de este término. Así lo explicita Laporta, cuando dice que "empieza a detectarse en la literatura especializada una cierta alarma ante la creciente y la no infrecuente ligereza de apelaciones a los derechos humanos" (Laporta 1989: 23). Se trata de un concepto polisémico.

Los derechos humanos aparecen en el imaginario social de la cultura occidental representados a través de las normas jurídicas que emanan del Estado y que llevan implícitos valores como la libertad, la igualdad y la solidaridad y cuya principal referencia es la Declaración Universal de los Derechos Humanos (1948). A partir de ella aparecen tales derechos reconocidos tanto en el ámbito internacional como nacional, en las constituciones, normas fundamentales, cartas magnas...En el mejor de los casos, se piensa en la necesidad de articular garantías (Ferrajoli 1991) a través de instrumentos internacionales y nacionales. Asimismo, se alude a un listado más o menos cerrado, que refleja la sensibilidad de la época, específicamente de la sociedad occidental moderna. Las formas jurídicas actuales responden a las lógicas liberales burguesas que presentan el derecho y las normas como si fueran un sistema racional positivo independiente de los intereses económicos y sociales que sustentan su propia razón de ser. Esta lógica racional positiva es la que impera cuando se habla de derechos humanos en el tema que nos ocupa. Los discursos institucionales de trata con fines de explotación sexual se fundamentan sobre la reivindicación de la puesta en marcha de medidas legislativas por parte de los Estados para combatirla, siguiendo las directrices marcadas por el Protocolo de Palermo. 
La importancia que tiene el Protocolo de Palermo está en que, además de clarificar conceptualmente la trata de personas desde una perspectiva abierta e incluyente, reconoce la necesidad de proteger una serie de derechos en las víctimas: derecho a obtener información sobre procedimientos judiciales y administrativos, así como a asistencia jurídica, a disfrutar de medidas para la recuperación física, psicológica y social, a tener un alojamiento adecuado, a disponer de oportunidades de empleo, educación y capacitación, a ser protegidas contra la re-victimización... El Protocolo (art. 2) explicita que su finalidad es triple: prevenir y combatir la trata de personas, prestando especial atención a las mujeres y niños, proteger y ayudar a las víctimas de dicha trata, respetando plenamente sus derechos humanos y promover la cooperación entre los estados parte para lograr esos fines.

Desde la lógica racional positiva, la ratificación del Protocolo para algunos de los Estados supondría legislar en favor de la consecución de los tres objetivos, pero en la práctica la mayoría de los países "desarrollados" han dedicado sus esfuerzos normativos a vigilar la libre circulación de personas (no de capitales), ejerciendo controles fronterizos para la regulación de personas indocumentadas. De tal manera que "al menos en la Comunidad Europea, el Estado legitima y realimenta las fobias sociales, relacionando conceptualmente migración y delincuencia" (Juliano 2005: 90).

El desarrollo normativo se aleja de los objetivos de prevención y protección de los derechos humanos de las víctimas, pero sí promueve la colaboración entre los Estados para reducir el número de personas migrantes ilegales mediante leyes y estrategias políticas represivas y comúnmente aceptadas. Se trata de una colaboración que desvirtúa la finalidad que perseguía el Protocolo de protección a las víctimas, por una colaboración de los Estados en favor de una protección de las fronteras. Por tanto, se promueven normas jurídicas que clasifican a las personas en categorías de ciudadanos y migrantes. Y entre estos últimos establece la distinción entre los derechos conferidos a personas migrantes que están legalmente en un país distinto al de ellas y las que se encuentran en situación irregular. Con lo cual se establece una "jerarquía" de beneficiarios, como ha señalado Richard Perruchoud (CEPAL 2003: 27): ciudadanos que gozan de plenos derechos; migrantes instalados legalmente en el territorio del Estado; y migrantes en situación irregular, los cuales se hallan más expuestos a situaciones de abuso o discriminación, y entre estos particularmente las víctimas de trata de personas. Pues se sabe, en efecto, que víctimas de la trata transnacional cruzan las fronteras de otros países ajenos al suyo de origen, de manera irregular, lo que las sitúa en una mayor vulnerabilidad por no conocer el contexto sociocultural y por carecer de redes de apoyo. Las redes mafiosas son, como explica Solana, una de las estrategias utilizadas por las mujeres migrantes para salir de sus países. "Se trata de grupos organizados, con diferentes ramificaciones enlazadas entre sí, que se encargan de todo el proceso migratorio (reclutamiento/captación, organización y transporte, recepción, acogida y traslado a España) y que se sirven de violencia, coacción o amenazas para explotar a las mujeres" (Solana 2007: 48).

Esta lógica punitiva es la que marca las disposiciones legales que regulan las medidas de protección a las víctimas, insistiendo en la importancia de la denuncia y condicionando la atención a la colaboración con la justicia. Las disposiciones legales otorgan un especial protagonismo a las fuerzas de seguridad y a los operadores jurídicos, mientras las víctimas corren el riesgo de ser invisibilizadas o, lo que es peor, de ser cosificadas, pasando a convertirse de nuevo en meros objetos, pero esta vez al servicio no ya de tratantes sino del propio sistema judicial. De esta forma, se olvida el hecho principal: que es la protección de personas inocentes, vulnerables y que tienen gravemente lesionadas violentamente las condiciones para lograr conquistar una vida con dignidad.

Otro de los aspectos polémicos que fondea en el enfoque normativo es la asimilación de trata de personas sometidas a explotación sexual con prostitución. Compartimos con Juliano (2005: 96) la siguiente afirmación:

"Pese a la separación que la legislación internacional actual permite hacer entre trata y prostitución, el modelo anterior que confunde ambos términos se perpetua en las campañas abolicionistas actuales, con posiciones que se reflejan en la prensa y cuyo dramatismo oculta el hecho que las trabajadoras sexuales, pobres o inmigrantes tienen problemas comunes con el resto delas trabajadoras, al mismo tiempo que dificulta considerarlas como agentes activos de sus opciones y portadoras de proyectos específicos".

La lógica normativa dominante se debate entre dos planteamientos opuestos: quienes reclaman la legalización de la prostitución y quienes defienden su abolición. La posición que defiende la legalización de la prostitución llega a comparar el trabajo en la prostitución con otras experiencias laborales (Solana y López 2012). La posición abolicionista es la dominante en la normativa europea, donde se defiende como 
argumento principal que la prostitución siempre va de la mano de la violencia contra las mujeres, influyendo decisivamente en el aumento del tráfico y la trata de mujeres con fines de explotación sexual. Estos debates que vinculan directamente trata y prostitución están presentes en las normativas internacionales y nacionales puestas en marcha por los Estados.

En las cifras facilitadas por los organismos internacionales se aprecian los vínculos entre mujeres migrantes extranjeras, víctimas de trata y prostitución. Pero conviene precisar que aunque son numerosas las víctima de trata con fines de explotación sexual obligadas a ejercer la prostitución, eso no significa que todas las mujeres migrantes que ejercen la prostitución sean víctimas de trata. La confusión en la identificación de ambos situaciones conlleva no solo la dificultad de identificación de las víctimas de trata, sino que invisibiliza la vulneración de derechos que supone esta forma de esclavitud. De ahí la importancia de plantear un enfoque de Derechos Humanos con perspectiva de género, tal y como recomienda Sara García: "las violaciones de Derechos implícitas en la trata están vinculadas a la división sexual del trabajo, afectando de forma diferencial a hombres y mujeres más allá de la explotación sexual. A su vez, la trata con fines de explotación sexual se reconoce ya formalmente como una forma de violencia de género y una violación específica de los Derechos Humanos de las mujeres" (García 2012: 60-61).

Resumiendo, se puede decir que el enfoque normativo de los derechos humanos que domina el abordaje de la trata con fines de explotación sexual, resulta limitativo porque no incide en los problemas estructurales de orden socioeconómico (pobreza, falta de educación, subdesarrollo, desigualdades de género...). La medida que la mayoría de los instrumentos internacionales de derechos humanos (elemento normativo e institucional) tienen aprobada hasta el momento, prevé que los Estados deben respetarlos y asegurarlos a cualquier persona en su territorio, sin importar su condición jurídica, sea ciudadano o migrante, pero en la práctica se imponen una serie de limitaciones para el acceso y el goce de esos derechos, particularmente para las personas migrantes $y$, por supuesto, para aquellas invisibilizadas por el flagelo de la trata de personas.

\section{Derechos humanos con enfoque crítico}

El abordaje de los derechos humanos desde la teoría crítica nos permite ampliar la mirada al fenómeno de la trata desde una perspectiva compleja, superadora de la simplicidad del enfoque normativo. Una perspectiva que reconoce la importancia del momento normativo e institucional, pero que lo sitúa como un componente de muchos otros necesarios y que vayan más allá de este.

Desde este enfoque, los derechos humanos no son considerados principios absolutos, pues, como se ha venido exponiendo, ni siquiera la existencia de unos dispositivos normativos o de unas instituciones internacionales o nacionales, son garantía efectiva de protección para las personas, particularmente de aquellas vulnerabilizadas por las condiciones de vida impuestas y victimizadas por la acción de grupos organizados, como el caso de las mafias de la trata de personas.

Para afrontar el fenómeno de la trata con fines de explotación sexual es necesario incorporar una sensibilidad de derechos humanos humanos crítica, compleja y socio-histórica (Sánchez y Senent 2013), que permita orientar la acción social e institucional a la satisfacción de necesidades humanas y a una sociabilidad humanizadora. De esta forma, la sensibilidad de los derechos humanos se hace cargo de la parcialidad y limitación que supone cualquier postulación de derechos, ya que estos no se deben considerar como un canon cerrado, sino más bien como un horizonte abierto en el que, conforme a las nuevas situaciones, se van descubriendo espacios de humanidad cada vez más amplios que reclaman protección y que al mismo tiempo van mostrando nuevos campos de reivindicación y lucha por derechos humanos.

Desde el enfoque crítico, los derechos humanos son considerados como un conjunto de procesos sociales, económicos, normativos, políticos y culturales que abren y consolidan desde el reconocimiento, a la transferencia de poder, la producción cultural y la mediación jurídica. Los derechos humanos, en fin, deben ser considerados como espacios de lucha social (Herrera 2005) por la dignidad humana, generando relaciones sociales emancipadoras frente a las estructuras de opresión.

Desde esta perspectiva crítica, las acciones contra la trata de personas con fines de explotación sexual deben orientarse en lo coyuntural inmediato a desmontar y sancionar las estrategias de los grupos organizados (mafias), así como a dar soporte a las víctimas para su recuperación cuando son sacadas del circuito de la trata de personas. Pero, a la vez, se deben orientar a la desactivación de los dispositivos 
estructurales que facilitan esta forma de esclavitud, como son los de orden socioeconómico; tales, la pobreza, la falta de educación y las condiciones de "maldesarrollo", pero también los de orden sociocultural, como la visión estatalista y burocrática de los derechos, el patriarcado y el orden paterno-gerontocrático, por señalar algunos (Cordero y otros 2012).

La mirada crítica permite ver las correlaciones entre la falta de incidencia efectiva en los problemas estructurales de orden socioeconómico (las ya dichas pobreza, falta de educación, maldesarrollo) con la visión estatalista de los derechos. Y esto se dice como una crítica ya apuntada, en la medida en que la mayoría de los instrumentos internacionales de derechos humanos (desde las lógicas normativas) se proponen lo que no cumplen: que los Estados deben respetarlos y asegurarlos a cualquier persona en su territorio, sin importar su condición jurídica, sea ciudadano o migrante. La verdad es que en la práctica, según ya hemos dicho, se imponen una serie de limitaciones para el acceso y el goce de esos derechos, particularmente para las personas migrantes y para las que son invisibilizadas por la esclavitud que supone la trata de personas. Por lo demás, los Estados cuentan con márgenes de apreciación o de discreción para determinar restricciones en la realización de los derechos de las personas. No se puede olvidar que están sobre todo las restricciones vinculadas con el funcionamiento de la lógica dineraria de las economías occidentales contemporáneas, toda vez que hay una especie de connivencia entre universalismo jurídico y economía monetaria, tal como señala Barcellona (1992).

En definitiva, la trata de personas pone en cuestión la existencia de la humanidad como especie, según lo recordara acertadamente Helio Gallardo (2011) y, sobre todo, genera un vaciamiento social, pues crea "no lugares" para todas aquellas personas víctimas, sobre las cuales su victimario o tratante puede disponer dónde ubicarlas (desarraigo) y cómo utilizarlas (instrumentalización). Asimismo, desnuda uno de los aspectos más perversos de una sociedad cuyo sistema de producción y reproducción de la vida está dado por la lógica dineraria, como única posibilidad validada de relación y de construcción de un proyecto común (Barcellona 1992).

El enfoque crítico de los derechos humanos alude a la obligatoriedad de los Estados de proveer mecanismos eficientes para evitar la impunidad de las mafias y que generen un entorno de protección para las personas que padecen situaciones de explotación sexual. Para lograrlo es necesario el compromiso de toda la sociedad, superando la connivencia con las redes de tratantes y desterrando las claves culturales que fomentan el desprecio por la condición humana, cuya otredad es negada o invisibilizada. Un entorno institucional, normativo y cultural que esté claramente orientado a las personas, particularmente aquellas más vulnerabilizadas por las condiciones de pobreza y exclusión, a salvo de la explotación y la trata. Esta es la empresa que demanda y compromete a mayores esfuerzos frente al presencia de tantas personas sometidas a la esclavización por parte de tratantes y victimarios.

El enfoque crítico de derechos humanos revela todas las aristas estructurales que sostienen el problema de la esclavitud sexual y señala la implicación necesaria de toda ciudadanía para combatir las graves vulneraciones de derechos que provoca en las personas. La complejidad del problema puede empezar a abordarse rompiendo con estereotipos tal como se aprecia en las palabras de García (2012: 51):

"La trata no es solo ese rapto de mujeres protagonizado por oscuros criminales. No es un hecho disonante con un mundo alejado de la brutalidad del pasado. La realidad es que la trata ocupa un lugar funcional en la sociedad. Si este terrible suceso sigue teniendo éxito es porque constituye una prolongación de una estructura de división social y sexual del trabajo hacia las periferias de la economía sumergida. La trata se localiza donde la explotación laboral extrema resulta posible y rentable".

\section{Normativas y acciones institucionales: el caso de España}

Los últimos informes de Naciones Unidas consideran que España es país de origen y de tránsito de víctimas procedentes de Brasil, América del Sur y África, al mismo tiempo que también ocupa un lugar destacado como destino, recibiendo a víctimas procedentes de Colombia, República Dominicana, Nigeria, Rusia, Ucrania, Rumanía, Bulgaria, Brasil, Croacia, República Checa, Hungría, Marruecos, Polonia y otros países (Ministerio del Interior 2008: 7). Ante esta situación, el estado español ha puesto en marcha normativas y planes de acción para combatir la trata de persona. Aunque estas suponen un avance en el reconocimiento del problema y han generado algunos cambios importantes en las normativas vigentes, la implementación de políticas públicas preventivas y que garanticen una atención integral a las personas que padecen situaciones de trata aún está lejos de alcanzarse. 
Uno de los referentes principales en el ámbito europeo es el Convenio del Consejo de Europa sobre la Lucha contra la Trata de Seres Humanos de 2005, también conocido como Convenio de Varsovia. Este Convenio junto a la Directiva de la Unión Europa de abril de 2011 constituyen el marco de referencia en el que el Estado español debe basar su respuesta ante el fenómeno de la trata de seres humanos con fines de explotación. Dicho Convenio hace alusiones claras a la vulneración de derechos que supone la trata de personas: "En efecto, la trata de seres humanos constituye uno de los atentados más intolerables contra los derechos humanos, significadamente en cuanto lesiona gravemente la dignidad de la persona" (2005: 2). Otros aportes importantes son el señalamiento de que el abordaje de la trata requiere una mayor protección para las víctimas y menciona que no sólo es un fenómeno transnacional, sino también nacional, tomando en consideración la igualdad de género.

La incidencia directa del Convenio de Varsovia ( 2005) en la legislación española se puede apreciar en la modificación en el Código Penal en 2010 que tipifica la trata como delito y en una modificación en la Ley de extranjería LOEX ( 2011) que reconoce la necesidad de protección a las víctimas de trata. La Ley Orgánica $5 / 2010$, en su Título VII bis, "De la trata de seres humanos", establece el delito de trata de personas que consiste en: captar, transportar, trasladar, acoger, recibir o alojar, empleando violencia, intimidación o engaño, o abusando de una situación de superioridad o de necesidad o de vulnerabilidad, con cualquiera de las finalidades prevenidas en dicha artículo. Entre las finalidades citadas se encuentra la explotación. Anteriormente a esta ley, existía la Ley Orgánica 10/1995, de 23 de noviembre, del Código Penal, en la que los Artículos 188 y 318 bis 2 eran sancionados los delitos correspondientes a que una persona determine que otra ejerza la prostitución y la facilitación del tráfico ilegal o la inmigración clandestina de personas respectivamente. Con respecto a la Ley Orgánica sobre derechos y libertades de los extranjeros en España y su integración social, se incorpora un nuevo artículo 59 bis sobre Víctimas de la Trata. Este recoge la necesidad de adoptar medidas para la identificación de víctimas de trata por parte de las autoridades, de acuerdo con lo previsto en el artículo 10 del Convenio del Consejo de Europa sobre la lucha contra la trata de seres humanos. Dicha medida de protección se aplicará a las víctimas de trata que se encuentren en el país en situación administrativa irregular o con un permiso de residencia temporal, con el fin de hacer frente a la situación de extrema vulnerabilidad en la que se pueden encontrar tras la experiencia traumática sufrida. La novedad principal es que se establece el derecho a un periodo de restablecimiento y reflexión para las víctimas y supuestas víctimas, entre otros derechos desarrollados posteriormente en el reglamento de la Ley. De este reglamento se ha derivado el Protocolo de Coordinación para la identificación y protección de víctimas que establece el procedimiento para garantizar sus derechos, y la coordinación con entidades especializadas.

Como se viene diciendo en el caso de España, no existe ley nacional contra la trata, sin embargo el Ministerio del Interior lanza, en 2008, el Plan Integral de Acción contra la trata de seres humanos con fines de explotación sexual. Análisis de situación y Plan de Acción. Este plan en la actualidad ha culminado su periodo de aplicación, pero hasta el momento el gobierno de España no se ha pronunciado sobre cuáles van a ser, a partir de este momento, sus líneas estratégicas para combatir la trata.

En el capitulo segundo del Plan Integral se hace mención al desarrollo de medidas integrales en la asistencia y protección a las víctimas. En estas se reconoce la necesidad de establecer una serie de garantías para las víctimas, concediendo un período de reflexión previo a la denuncia que resulte suficiente para que la víctima pueda restablecerse y escapar a la influencia de los traficantes y/o pueda tomar una decisión en lo relativo a su cooperación con las autoridades competentes. Es decir, que las garantías de protección estarán vigentes tan solo durante el periodo de reflexión y si existe una posterior denuncia por parte de las víctimas, estableciendo una relación condicional entre la colaboración con la justicia y la posibilidad de recibir atención derivada de la influencia de la lógica punitiva. En palabras de García (2012: 54): "en España, la tendencia en la práctica sigue siendo -en no pocos casos con seguimiento-, según estas informaciones, la de anteponer el interés por la persecución del delito antes que el restablecimiento de los derechos de las personas agredidas y la salvaguarda de sus posibilidades de su recuperación inmediata".

Revisando las acciones políticas institucionales emprendidas por el estado español (Acien y Checa 2011) se puede afirmar que la atención a las víctimas de trata con fines de explotación sexual, en España, recae fundamentalmente sobre las ONG.

En el año 2005 nace la Red Española contra la Trata de Personas dada la necesidad creciente de responder, de forma articulada y como sociedad civil, a las situaciones derivadas de la trata. La idea surge de la exigencia de poner en común las experiencias y diferentes abordajes de esta temática y trabajar conjuntamente por aunar esfuerzos de forma coordinada para incidir en las políticas nacionales. Se puede 
afirmar que son las organizaciones de la sociedad civil las que viene asumiendo desde hace décadas el trabajo de atención a las personas víctimas de trata. El trabajo de la Red Española es una iniciativa que trata de superar sus diferencias (Acién y Checa 2011) políticas e ideológicas para poner en común buenas prácticas y ejercer su influencia en las políticas públicas, exigiendo al gobierno de España que cumpla y concrete sus compromisos con los tratados internacionales.

El gobierno español se desvincula de la asistencia, defendiendo que son este tipo de organizaciones las conocedoras de la situación contextual y emocional de las víctimas de trata. En el último informe del Defensor del Pueblo (2012) se defiende que la participación formal de las organizaciones no gubernamentales especializadas en el procedimiento de identificación de las víctimas para garantizar los derechos y necesidades de las víctimas de trata de seres humanos, es un elemento fundamental Sin embargo, dicho informe reconoce que en la práctica la intervención de las entidades depende exclusivamente de la decisión que tomen los funcionarios en cada caso. Por tanto, resulta imprescindible abordar la evaluación del procedimiento seguido hasta el momento. Estamos de acuerdo en que es necesario unir fuerzas y conocimientos para luchar contra este tipo de esclavitud, pero la implicación de la sociedad civil no debe ser una excusa para que el gobierno de España se exima de su responsabilidad institucional en la asistencia y protección de las víctimas.

Sintetizando, se podría decir que en España existe un par de disposiciones legales que refuerzan tanto el control migratorio como la confusión con la prostitución. La primera de esas disposiciones sigue la lógica criminalista de persecución del delito, asimilándolo al de tráfico ilícito y la segunda asimila trata a prostitución, centrada de forma simplista en las mujeres y sin incorporar un enfoque más amplio sobre género y derechos humanos. La asistencia y atención a las víctimas está delegada en una parte de la sociedad civil, como son las ONG, de forma que la mayor parte de la población está ajena a las vulneraciones de derechos que padecen las personas en situaciones de trata con fines de explotación sexual.

\section{5. ¿Mal-trato institucional o acciones transformadoras?}

Como se ha venido exponiendo, la trata de personas con fines de explotación sexual es un problema creciente en el mundo entero, empujado por las situaciones de crisis que han llevado al empobrecimiento de familias, comunidades y personas, por lo que se requieren abordajes críticos y holísticos que generen acciones humanizadoras sobre quienes padecen esta grave vulneración de derechos.

El enfoque crítico permite descubrir cuáles son las causas que provocan que las mujeres y las niñas sean las personas más afectadas por la trata con fines de explotación sexual, tal y como apuntan todas las estadísticas. De esta forma se podrá enfrentar el problema no sólo desde acciones posviolatorias de derechos humanos sino también previolatorias.

Las principales causas estructurales son, por un lado, las derivadas de la feminización de la pobreza: el poco acceso a oportunidades y recursos empuja a muchas a intentar buscar mejores condiciones de vida para los suyos. Por otro, la dominación patriarcal que considera a las mujeres "un ser para otros", genera una inequidad que ha llevado a tomar los cuerpos de las mujeres y someterlos al servicio de los demás. Se puede afirmar que la trata es una realidad que maltrata de forma especial a las mujeres y responde una lógica en la que "el contrato social, vampirizado y en suspenso, cede su espacio a los pactos entre el poder mafioso y el poder corrupto que llegan a convertirse en un "estado paralelo" (Amorós 2008: 245).

Las condiciones de esclavitud a las que son sometidas las mujeres se sustentan sobre la violencia de género, cuyo objetivo es mantener las situaciones de subordinación de estas y la primacía de lo masculino. En las actuaciones de trata con fines de explotación sexual es necesario visibilizar que las mujeres padecen maltratos por explotación laboral, violencia física, sexual, patrimonial, y que se las engaña, manipula y chantajea, además de que se las priva de su libertad. En este sentido, la trata de personas es un eslabón más en la cadena de violaciones a los derechos humanos de las mujeres, violación que tiene carácter estructural y sociocultural, alcanzando también a hombres, niños y niñas, adolescentes que son víctimas de este delito.

Estos marcadores estructurales de violencia y de desigualdad contra las mujeres y los colectivos más vulnerables son reflejados explícitamente en la propia función que cumple el enfoque normativo. Se trata de lo que, en la literatura criminológica, se ha denunciado tantas veces como la "doble (y múltiple) victimización" 
que sufren los sujetos víctimas de un delito, al ser sometidos a los procesos judiciales orientados a reprimirlos o sancionarlos. El diseño del proceso judicial, que busca establecer una "verdad procesal" (Ferrajoli 1995), necesita "recrear" los hechos enjuiciados, por lo cual tiene que revivir las situaciones que las personas han sufrido. Esa "recreación" supone un cierto ensañamiento "bien intencionado", al someter a las víctimas a procesos de rememorización de todo lo vivido y, lo que es peor, en no pocos casos de publicitación de su vivencia conflictiva, que pasa a ser parte de la memoria colectiva que la señalará permanentemente. En ese sentido, Susana Chiaroti ha señalado:

"En el delito de trata de mujeres, suele pasar algo similar a lo que ocurre con los delitos de violencia sexual: la víctima termina siendo la acusada. Este proceso se da en los tribunales de justicia locales a la hora de juzgar delitos como la violación, el estupro o el abuso sexual. El eje de la investigación se desvía del acusado hacia la víctima y continúa con el análisis de la conducta de esta última, sus antecedentes personales, sobre todo en lo relativo a su vida sexual" (CEPAL 2003: 54).

Las propias cifras reflejan el fracaso del enfoque normativo. Según datos recogidos en el último Informe del Defensor del Pueblo (2012) en Europa, solo se detecta una de cada 20 potenciales víctimas de trata con fines de explotación sexual. En el mismo informe se confirma que en España el número de víctimas detectadas es muy bajo en relación con las personas identificadas en situación de riesgo: en 2009 se identificaron 1.301 víctimas, frente a las 6.157 personas detectadas en situación de riesgo; en 2010 se identificaron 1.641 víctimas, frente a 15.075 personas detectadas en situación de riesgo; y en 2011 las víctimas identificadas fueron 1.082, frente a 14.730 personas detectadas en situación de riesgo.

La falta de denuncias puede interpretarse claramente como un maltrato institucional y los procedimientos poco amigables a los que tienen que someterse quienes deciden revelar las condiciones de esclavitud a las que han sido sometidas. Dichos procedimientos, además, obvian las creencias culturales que llevan a muchas mujeres a negar las propias situaciones que padecen: a veces, porque temen represalias de las redes, de sus familias, de las fuerzas de seguridad que las pueden detener o expulsar del país, o por el estigma provocado por el hecho de haber sido explotadas. "En otros casos, el silencio de las víctimas está motivado por la dificultad de aceptar el fracaso de un intento migratorio, porque los sueños buscados no se han alcanzado o por la existencia de cargas familiares que la persona víctima ha de sostener" (Agustín 2003: 73-74 y 113).

El mal trato institucional también se refleja en la homogenización abstracta de las "víctimas de trata". Estas mujeres comparten perfiles y elementos comunes como el engaño, la coacción, la explotación..., pero esto no implica la consideración de una categoría standard. Cada una ha de ser atendidas en su individualidad: con nombre propio, identidad, procedencia y situaciones jurídicas, sociales, familiares y culturales particulares, que han de ser reconocidas en las prácticas institucionales. La negación por parte del enfoque normativo e institucional de las particularidades culturales de cada una de las mujeres que padecen situaciones de explotación sexual, provoca un mal trato añadido que se concreta en comportamientos por parte de los cuerpos y fuerzas de seguridad del Estado, como desvalorización, exclusión, discriminación, calificación negativa, descalificación y sojuzgamiento fundamentados en un cultura patriarcal imperante el enfoque normativista.

Por consiguiente, una tarea impostergable en la lucha por los derechos humanos, tiene que ver con la acciones transformadoras que provoquen procesos culturales no re-victimizantes, que tiendan a superar los prejuicios y los estereotipos sociales (como la sutil culpabilización de las víctimas por la situación vivida), a la vez que sensibilice a las personas implicadas en la lucha contra la trata (policías, jueces, funcionarios, etc.) para que la víctima pueda ingresar en procesos de construcción de reconocimiento, personal y social, con entornos seguros y sanadores, para ella y sus familias.

Desde el enfoque crítico de los derechos humanos prevalece la importancia de generar procesos hermenéuticos que dignifique la atención a las mujeres y generen una comprensión más profunda y singular de las situaciones que están viviendo. En este sentido, resulta imperiosa la necesidad de reclamar, con la mediación de las instituciones, posibilidades de vida digna para las mujeres y niñas afectadas, dándoles voz y protagonismo en los procesos de lucha por su emancipación. El objetivo de las acciones transformadoras será devolverles la autonomía, partiendo del derecho de las mujeres de tomar sus propias decisiones en asuntos que afectan sus cuerpos y sus condiciones de vida. 


\section{Bibliografía}

Acién, Estefanía (y F. Checa Olmos)

2011 "La actualidad del abordaje de la trata de personas para la prostitución forzada en España. El Plan Integral y sus implicaciones para trabajadoras del sexo inmigradas", Gazeta de Antropología, n 27 (1), art. 08. http://hdl.handle.net/10481/15281

Agustín, Laura María

2003 Tráfico y prostitución: experiencia de mujeres africanas. Bilbao, Likiniano Elkartea.

Amoros, Celia

2008 Mujeres e imaginarios de la globalización. Reflexiones para una agenda teórica global del feminismo. Buenos Aires, Homo Sapiens Ediciones.

Barcellona, Pietro

1992 Postmodernidad y comunidad. El regreso de la vinculación social. Madrid, Trotta.

Comisión Económica para América Latina y Caribe (CEPAL)

2003 Derechos humanos y trata de personas en las Américas. Resumen y aspectos destacados de la Conferencia Hemisférica sobre Migración Internacional. Serie Seminarios y Conferencias $n^{\circ} 33$, Santiago de Chile.

\section{Consejo Europeo}

2005 Convenio del Consejo de Europa sobre la lucha contra la trata de seres humanos. Varsovia. http://www.accem.es/ficheros/documentos/pdf trata/Convenio_Consejo_de_Europa.pdf

Cordero, Nuria (y otros) (coord.)

2012 Trata de personas, dignidad y derechos Humanos. Sevilla, Arcibel.

Cordero, Nuria

2012 "Trata, mujeres y derechos humamos. Una mirada con enfoque crítico", comunicación al III Congreso para el estudio de violencia contra las mujeres. Justicia y seguridad, nuevos retos (Granada).

http://www.congresoestudioviolencia.com/2012/articulos.php

2013 "La trata de mujeres y niñas. (De) construyendo los derechos humanos", en José Ma Valcuende y otros (coords.), Diversidad sexual en Iberoamérica. Sevilla, Aconcagua.

Defensor del Pueblo

2012 La trata de seres humanos en España: Víctimas invisibles. Madrid.

http://www.defensordelpueblo.es/es/Documentacion/Publicaciones/monografico/contenido_1348128571191.htr

Ferrajoli, Luigi

1991 Derecho y razón. Teoría del garantismo penal. Madrid, Trotta.

1995 Derechos y garantías. La ley del más débil. Madrid, Trotta.

Gallardo Martínez, Helio

2011 "Migración, derechos humanos e identidades", en David Sánchez y Pilar Cruz Barcelona, Teoría crítica del derecho. Nuevos horizontes. Aguascalientes, Centro de Estudios Jurídicos y Sociales Mispat: 19-35.

García Cuesta, Sara

2012 "La trata en España. Una interpretación de los Derecho Humanos en perspectiva de género", Dilemata, (Unidad Asociada de Éticas Aplicadas IFS/CSIC), nº 10: 45-64.

Herrera, Joaquín

2005 Los derechos humanos como productos culturales. Madrid, Catarata.

Juliano, Dolores

2005 “El trabajo sexual en la mira. Polémicas y estereotipos”, Cuadernos Pagu, n² 25: 79-106.

1989 "Sobre el concepto de derechos humanos", Doxa, n 4: 23-45. 
Ley Orgánica 4/2000, de 11 de enero, sobre derechos y libertades de los extranjeros en España y su integración social. http://www.boe.es/boe/dias/2000/01/12/pdfs/A01139-01150.pdf

Ley Orgánica 5/2010, de 22 de junio, por la que se modifica la Ley Orgánica 10/1995, de 23 de noviembre, del Código Penal. http://www.boe.es/boe/dias/2010/06/23/pdfs/BOE-A-2010-9953.pdf

Ministerio del Interior

2008 Plan integral de lucha contra la trata de seres humanos con fines de explotación sexual. Análisis de situación y plan de actuación. http://www.intermigra.info/extranjeria/archivos/impresos/PlanTrataMIR.pdf

Mujeres en Zona de Conflicto (MZC)

2009 Cuaderno Campaña Stop Trata. http://stoptrata.mzc.org.es/descargas/cuaderno-stop-trata.pdf

Oficina de Naciones Unidas contra la droga y el delito (ONUDD)

2009 Informe mundial sobre la trata de personas. Resumen ejecutivo.

http://www.unodc.org/documents/human-trafficking/Executive_summary_spanish.pdf

Organización Internacional para las Migraciones (OIM)

2010 Glosario de términos trata de personas. Derecho aplicado.

http://extranjeros.empleo.gob.es/es/RedEuropeaMigraciones/glosario/EMN_Glossary_ES_Version.pdf

Organización de Naciones Unidas (ONU)

2000 Protocolo para prevenir, reprimir y sancionar la trata de personas, especialmente mujeres y niños, que complementa la Convención de las Naciones Unidas contra la Delincuencia Organizada Transnacional.

http://daccess-dds-ny.un.org/doc/UNDOC/GEN/N00/560/92/PDF/N0056092.pdf?OpenElement

Real Decreto 1162/2009, de 10 de julio, por el que se modifica el Reglamento de la Ley Orgánica 4/2000, de 11 de enero, sobre derechos y libertades de los extranjeros en España y su integración social, aprobado por el Real Decreto 2393/2004, de 30 de diciembre.

http://www.boe.es/boe/dias/2009/07/23/pdfs/BOE-A-2009-12208.pdf

Real Decreto 1162/2009, de 10 de julio, por el que se modifica el Reglamento de la Ley Orgánica 4/2000, de 11 de enero, sobre derechos y libertades de los extranjeros en España y su integración social, aprobado por el Real Decreto 2393/2004, de 30 de diciembre.

http://www.boe.es/boe/dias/2009/07/23/pdfs/BOE-A-2009-12208.pdf

Sánchez, David (y J. Antonio Senent)

2013 Teoría crítica del derecho. Nuevos horizontes. Aguascalientes, Centro de Estudios Jurídicos y Sociales Mispat, A. C.

Solana, José Luis

2007 "Movimientos migratorios, trabajadoras inmigrantes y empleo en la prostitución, Documentación Social (Madrid), nº 144: 37-57.

Solana, José Luis (y José López Riopedre)

2012 Trabajando en la prostitución: doce relatos de vida. Granada, Comares. 